\title{
Downwardly Converging Tandem Planes
}

\author{
A Promising Development on the Basis of Eiffel's Work
}

By Robert I. Andrew's

The brief report upon "tandom planes" made by M. Eiffel in the second edition of his monumental work on "The Resistance of the Air and Aviation," is remarkable for many reasons. For one thing it proves that at last a means has been found for giving a following plane its full efficiency. In addition, there is precise intormation regarding the movements of the center of pressure upon downwardly converging tandem planes, which is of great significance. But even more noteworthy are the logically involved evidences of a dynamic relation hetween front and rear planes of this description whose existence seems hitherto to have escaped general attention. While M. Eiffel states that he has only sketched out these systems and expects t• contmus his experiments upon them, sufficient data are given to enable us to draw some very interesting conclusions leading to the final inference that in the tandem arrangement of downwardly converging planes are found a number of the requisites of the ideal aeroplane. On this a it is of value to develop the information we have in some detail.

M. Eiffel's experiments on tandem planes included three different arrangements or "systems," as he call them. In each two similar planes were used, of eircu lar curvature, with the depth of the chord $1 / 13.5$ of its length. Each plane measired 15 by 90 centimeters, and they were spaced 30 centimeters apart. In System I, the chords of the two planes were in a straight line. In System II, the rear plane was tilted forward at a In System II, the rear plane was tilted forward at a
negative angle of 2.5 degrees. In System III, the rear plane had a negative angle of 5 degrees. Sce dagram.

The planes used are identical with that which $\mathbf{M}$ Eiffel has found by comparison with many others to be most generally efficient and which he has adopted in his report as a standard for estimating relative values.
It is designated Wing No. 3 . In his chart of curves, giving the results of the tandem experiments. the curve of this standard $1 / 13.5$ surface as a monoplane is also plotted. Since in these charts all results are reduced to common terms per unit of supporting surface, a comparison of surfaces of different areas is made possible. In addition to the (harts, there are given in the annex the figured resultants of each system of tandem planes. By reterence to these and the resultants of the single standard plane, we are enabled to calculate the parts performed by the rear planes of each system. We know what the front surface does when taken alone, and what both surfaces do in conjunction; hence, we find at once the work done by the rear surface. The facts thus brought to light are so extraordinary that they merit the elosest attention.

We quote below from M. Eiffel's tables showing the drift $\left(R_{x}\right)$ and the lift $\left(R_{\eta}\right)$ and the ratio between them $\left(R_{x} / R_{l \prime}\right)$ of the three systems, with the wind striking below the front plane at the successive angles of $3,6,9$, and 12 degrees. The unit of resistance is 1 gramme per square meter of surface.

TABLE I. - ANGLE OF INCIDENCE FOR FRONT PLANE. System I. No Convergence.

$\begin{array}{lcccc} & 3 \text { deg. } & 6 \text { deg. } & 9 \text { deg. } & 12 \text { deg. } \\ \text { Drift..... } & 123 & 155 & 211 & 274 \\ \text { Lift ..... } & 665 & 987 & 1,315 & 1,540 \\ \text { Ratio.... } & .19 & .16 & .16 & .18\end{array}$

System II. 2.5 deg. Convergence Downward.

$\begin{array}{lcccc} & 3 \text { deg. } & 6 \text { deg. } & 9 \text { deg. } & 12 \text { deg. } \\ \text { Drift. ... } & 141 & 167 & 219 & 291 \\ \text { Lift..... } & 1,094 & 1,568 & 2,068 & 2,326 \\ \text { Ratio... . } & .13 & .11 & .11 & .12\end{array}$

$\begin{array}{llll}\text { Ratio.... } & .13 & .11 & .11\end{array}$

System III. 5 deg. Conergence Downward.

$\begin{array}{lcccc} & 3 \text { deg. } & 6 \text { deg. } & 9 \text { deg. } & 12 \text { deg. } \\ \text { Drift..... } & 129 & 145 & 181 & 246 \\ \text { Lift..... } & 334 & 703 & 965 & 1,347\end{array}$

$\begin{array}{llrrr}\text { Ratio.... } & .39 & 21 & .19 & 1,347 \\ & & & & \end{array}$

Since comparison shows that there is no very striking difference in the amounts of drift for the three systems, while their lifts vary in an extraordinary way, we will combine the latter in another table for more careful examination, recurring later to the matter of drift.

This tablo brings out the very curious fact that System II, which is mediate to the two others, exceeds them greatly in lifting power, carrying, in an average of positions, half as much again as System I, and twice as much as System III. Furthermore, when we remember that for the same angle of incidence, the front planes of earch system are doing exactly the same amount

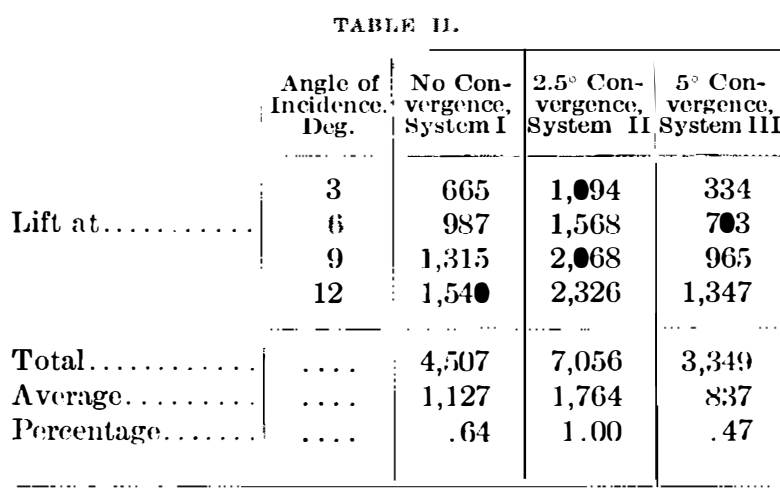

of work, and that the incquality of total result is due solely to the positioning of the rear planes, the significance of these facts becomes yet more impressive. In the next table are shown the parts performed by the fron and rear planes, respectively, of System II. This is done hy employing for the front plane at the successive
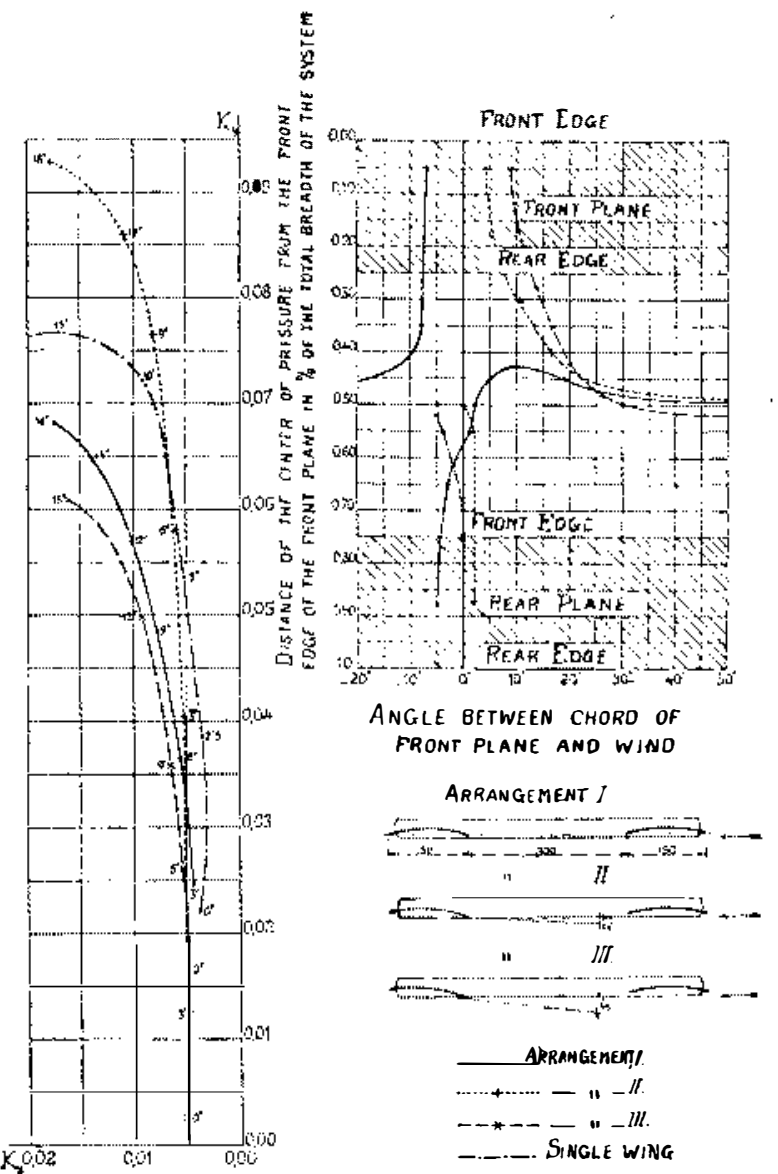

Eiffel's Lialylam of Lift and I)rift and Center of Pressure.

angles indicated, the values belonging to this plane when used alone as Wing No. 3.

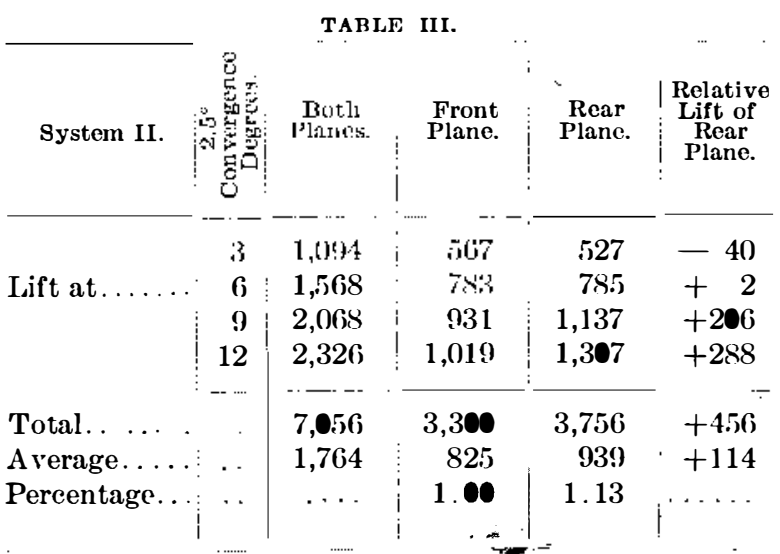

Lift $\left(R_{y}\right)$ of the two planes in System II.

Incredible as the conclusions of the above table appear, they follow as a mathematical necessity from the data established by M. Eiffel. The table shows that for an average of positions of from 3 to 12 degrees of incidence the lifting power of the rear plane is increased by 13 per cent over that of the front plane, when these are disposed as in System II.

Now let us consider the variations of lift by the rear plane which would occur if the planes were first set in the position of System I and the rear plane were moved successively to the positions it occupies in the other systems, i. e., to the negative angles of 2.5 and 5 degrees. We will assume that the wind has a constant angle of infidence relative to the front plane of 3 degrees. Using as a constant for the lift of the front plane the value above employed, 567, we may construct table IV. TABLE IV.

Table of Lifts with wind constant at 3 degrees incidence and the rear plane at different angles of adjustmerst.

\begin{tabular}{l|c|c|c} 
Lift with Rear Plane, as in & $\begin{array}{c}\text { Both } \\
\text { Planes. }\end{array}$ & $\begin{array}{c}\text { Tront } \\
\text { Plane. }\end{array}$ & $\begin{array}{c}\text { Rear } \\
\text { Plane }\end{array}$
\end{tabular}

\begin{tabular}{|c|c|c|}
\hline System I. No eonvergence & 665 & 567 \\
\hline $\begin{array}{r}\text { System II. } 2.5 \text { degrees con- } \\
\text { ve igenee........... }\end{array}$ & & 567 \\
\hline vergence........... & $3: 34$ & 567 \\
\hline
\end{tabular}

Here we find that as the rear plane is tilted forward from $\bullet$ to -2.5 degrees, the lift increases enormously, to more than 500 per cent. Continue the inclination 2.5 degrees more, and the lift wholly disappears and a downward pressure ot 233 units takes its place. There is, therefore, a mean position for the rear plane where its lift greatly exceeds that of the positions closcly adjoining. This phenomenon is so unusual in nature and so marked in degree, that it imperatively challenges a solution. There is every reason to suppose that it is a product of the effect induced in the air by its contact with the front plane; but the precise character ot this effect and of the operation that ensues from it is not at first evident. That this phenomenon is due to the spatial relation of the two planes and is independent of the angle of flight is shown by the clear superiority of lift shown by System II over the others at all angles. In the opinion of the writer, an explanation may be found in the elastic reaction of the air to the passage of the front plane.

An elastic body is one which actively resists distortion of its normal form, which is only another way of saying that its molecular particles tend to retain and regain when lost their normal spatial distribution. Work must be done to crowd them together or pull them more apart. Conversely, where such work has been done, a nearly equal amount of work will be done been done, a nearly equal amount of work will be done
by the return of the particles to their normal positions. by the return of the particles to their normal positions. table cushion, and a host of other material things possessing elastrcity.

When air in motion comes in contact with a fixed inclined plane, as in the Eiffel experiments, there ensues a rarification or tension of the air above the plane, and a compression below it. As the mass of air passes beyond the plane, these two areas oppositely affected are left in direct conjunction. The lower area seeks relief from its state of compression by expansion in the direction of least resistance, which is upward. The energy of this movement carries it beyond its level of inception and results in an inversion of the primary condition, so that the upper area becomes compressed and the lower is put in tension. This vibration back and forth continues until the energy of reaction left in the air by the plane has become dissipated. These vibrations in the moving air, could they be seen instantaneously, would appear as a continuous wave issuing from the rear edge of the plane, tinuous wave issuing from the rear
and are so shown in Diagram 5.

and are so shown in Diagram 5 .
Now suppose that a second plane $C-D$, identical with $A-B$ but reversed, be placed at the same level with it and so that its front edge coincides with the wave line which marks the border between the oppositely affected areas, as shown in Diagram 6. Expressing tension and compression by the signs minus $(-)$ and plus $(+)$, it becomes evident that under

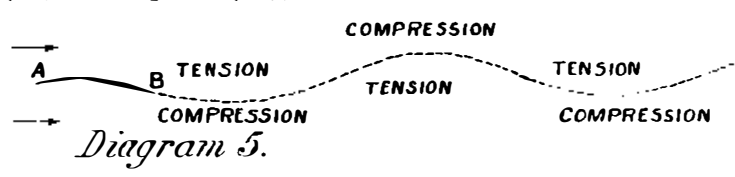

$$
\operatorname{Dingram}_{+}^{+} \sigma_{+}^{+}=\ldots
$$

theoretically perfect conditions all the positive pressure of reaction would be received on the under side of $C-D$ and all the negative pressures upon its upper side. In a word, the upward thrust upon $C-D$ would be the exact respondent of the downward thrust exelted by $A-B$. Furthermore, the inclination of the directions of pressure on the two planes would he inverted, and 
as the pressure is a retarding force upon the first plane, it appears as an accelerating force upon the second. The second plane is virtually gliding upon an ascending current.

It seems evident that under theoretically perfect conditions all the energy of reaction left in the air by the first plane would in this way be captured and utilized by the second, in which case there would be no loss of energy to the air. Of course this is practically impossible; but the thesis shows how any deviation from a right positioning of the second plane necessitates a loss of supporting efficiency. If the wave line passes above or below the second plane, relative failure ensues. This
is what we may suppose to occur in Systems I and III of M. Eiffel's experiments. In Table I the wave line passes below the rear plane; in Table III it passes above; while the efficiency of Table II is seemingly due to the fact that the wave line fairly meets it at its front edge.

This theory of elastic reaction of course cannot be regarded as any thing but a suggestion made to meet certain facts already familiar to the writer before tandem planes were made the subject of experiment by M. Eiffel. The behavior of free gliding models almost identical in fore and aft section with Eiffel's No. II is a convincing proof that some sort of interrelation of an unusual nature exists between the two planes. The matter seems deserving of the most careful investigation by physicists as well as engineers.

Let us pass now to a brief consideration of the movements of the center of pressure upon a system of downthat upon such a system as a single whole the shows of pressure advances continuously as the angle of inciof pressure advances continuously as the angle of incidence is lessened, until a point is reached when it passes
above the front edge and assumes a position upon the top of the rear surface. It is evident upon reflection that in such a system as Table II there is an intermediate condition when the front surface is receiving an upward pressure and the rear surface a downward pressure. But whatever the pressure or couple of pressures, they tend to the inherent stability of such a system in free flight. In his earlier report upon what he calls Wing No. 2, a plane of $1 / 27$ depth of chord and circular curvature, M. Eiffel shows the position of the center of pressure upon this surface at all possible angles throughout 360 degrees. Thus, we find it presented in positions where its concave side is upward, and here we find the center of pressure behaving in precisely the same way as in System.II above, running way forward to the extreme front edge below and then passing back to the rear above. It is evident therefore that this behavior of the centers of pressure upon downwardly converging tandem planes is not accidental but is inherent in that convergent relation, since it is consistently manifested when that relation occurs, and is manifested under no other known conditions. It should be noted, under no other known conditions. It should be noted,
also, that in System I, where there is no downward ron-

\section{Power from. Powdered Peat*} By Dr. J. McWilliam

Th is subject has been given a new interest from the exhaustive experiments of Lieut. Ekelund in Europe, and as I had used powdered peat to produce power at my peat factory near London, Canada, for two seasons four years ago, I have been requeste to give a short paper on the subject in order to bring before the society the possibilities that are contained
in this method of obtaining energy to drive machinery. in this method of obtaining energy to drive machinery. containing about 15 per cent moisure is quite equal in heat units to a ton of good soft coal, and, if properl applied, will go as far in raising steam as a ton of coal. Usually a ton of good soft coal is looked upon as equal to 1.8 tons of peat, that is air-dried machined peat. But Lieut. Ekelund claims that the combustion is so much more complete and the amount of air required is so much less in amount that the above result is obtained. The larger amount of air required in the combustion of a ton of coal has such a cooling effect on the boiler that much of the heat of the coal is lost, whereas the smaller amount of air required for the complete combustion of peat allows all the heat energy of the fuel to be delivered to the boiler.

Assuming that this is a fact that a ton of powdered peat is equal in heat giving properties, or nearly equal, to a ton of soft coal, then the method of obtaining powdered peat of a moisture content of 5 per

Lieut. Ekelund describes his method of digging the peat and air-drying it, of harvesting it in the form of blocks, at from 30 per cent to 50 per cent moisture content, according to the weather prevailing during a given season. At this point in the preparation of peat powder he describes methods of grinding, etc., which he has discarded, but does not tell us how he grinds it now, nor how he dries the powder to the point where

* Reproduced from the Journal of the American Peat Bociety. vergence of the planes, the center of pressure returns toward the rear edge as if the system were an ordinary monoplane. In regard to the matter of drift, earlier set aside here is no evidence for believing, and some for no believing, that the planes of constant curvature employed by $M$. Eiffel as tandem planes are better fitted to such use than planes of a parabolic or elliptical section, and that it is not improbable that in his further study of this subject the detrimental drift at low angles recorded by him may be reduced.

We may summarize these conclusions as follows:

Downwardly converging tandem planes give promise of securing from the air a larger measure of suppor for a given expenditure of propulsive energy than any form or system of surfaces now known. At the same upon them is what it should be ideally for the fullest possible degree of fore and aft stability, while in this respect all existing aeroplanes are conspicuously deficient it would seem that this system of surfaces is destined to supplant existing types of aeroplanes for general purposes.

\section{NOTE BY DR. A. F. ZAHM.}

Mr. Andrews' analysis of Eiffel's tandem monoplane experiments discloses some interesting relations based on the assumption that the forward surface, at a given speed and incidence, always encounters the same impactual pressure, whatever be the inclination of the rear one, and whether it be present or absent. This assumption, though in general not valid, may be approximately correct in the given instance.

To explain the remarkable wind force on the rear plane in Eiffel's experiment, Mr. Andrews surmises
plane explain the remarkable wind force on the rear that the air stream passing the front plane generates and transmits to the rear one a compressional wave
like that of sound, and this he illustrates by a horizontal wavy line. Thus while the air particles stream ing along the surface of the front plane are diverted downward and may pass well below the rear plane, a part of their energy may by molecular impulse be transmitted to the particles streaming past the rear
plane, and there exercise a marked effect on the surface pressure.

This molecular-transmission hypothesis of Mr. Andrews, to explain the increase of lift on the rear plane, differs essentially from the molar-rebound theory which assumes that the air stream emerging from the front plane rebounds en masse, and so exerts the observed effect on the rear plane. In 1893. Prof. J. J. Montgomery, one of the numerous reinventors of Boulton' three-torque control for aeroplane, informed the Aeronautical Conference at Chicago that he had allowed thistle down to float past an inclined plane in the open wind, and had observed that after passing the plane it pursued a course distinctly wavy as compared with
its line of approach. At a rather earlier date the present

it is an efficient fuel. As I have had some experience in grinding peat, and also in grinding peat powder, 1 am extremely curious to know the details of his method Had I those details I would have been in a much better Had I those details I would have been in a much better
position to calculate the cost of the whole scheme if carried out in our country. This grinding and drying of peat with 25 per cent to 50 per cent of water is a most difficult procedure. I cannot understand how he can grind it into a fine powder when it is so wet. Of course, he says he does it, and until we get a description of his pulverizing apparatus we must leave the matter there. He also says he dries it to 15 per cent moisture; granted that it is ground fine enough, I believe this can be done, but it is difficult, and a detaile account of his drier would interest me very much.

Our own experience with collecting and drying peat and from the first, has been commercially successful. We harrow the surface of the bog, exposing the broken peat to the influence of the sun and wind, which, in favorable weather, very quickly reduces a thin layer of peat to a moisture content of 25 per cent to 40 per cent. Over this prepared surface we pass a suction fan collector, which sucks up the dry material and leaves the wet. The peat is placed in our storehouse by this means as a finely divided powder, nearly all of it fine enough for use as a fuel under a boiler as applied by Lieut. Ekelund. Thus, by simply harrowing the bo and then sucking up the dust, we harvest our peat and grind it at one operation, also drying it to 25 of digging, stacking, carting and grinding being thus finished in a single operation. We have no absolute details of the cost of collecting a ton of this powder in this way, although many attempts have been made to get at the actual outlay. I never was quite satis fled, however, that every item of expense was included, and until we come to run commercially it will be difn-
cult to give an accurate statement. This much is writer observed that, as required by theory, the w ae from a down-arched horizontal wing also inclines rearwardly downward. A wavy line drawn obliquely downward with diminishing amplitude best indicates the observed phenomenon. Both these characteristics of the wake, its vabratoriness and its obliquity, were graphically recorded by Prof. Marey, by use of smoke streams and a camera, as shown in the ScIentific AM ERICAN for February 1st, 1902. These records show also the varying stress in the wake by the varying thickness of its marginal smoke stream-lines. The pulsatory variation of the air stress from point to point along a wing contour line from front to rear edge, on both the face and back of arched and plane surface inclined to a steady stream, is shown admirably in Eiffel's pressure diagrams for single surfaces exposed to a uniform wind.

The utilization of the "rebound" here in question has been a favorite scheme with many inventors, though they have been groping intuitively, instead of using Eiffel's illuminating quantitative method of ascertaining the much needed facts upon which rationally to base a practical invention. One plan has been to give the wing a reverse ${ }^{1}$ curve toward its rear; another has been to use an elastic trailing edge, as in Etrich's monoplane. Some years ago an inventor showed me a tandem arrangement of propeller blades in which the following blade was to be so positioned as to recover some of the energy expended by its forward mate. Perhaps som one will explain that ducks fly in tandem, or in $V$ ranks, partly for the same reason. More than a decade ago Mr. Mattullath contended that many birds catch with their tails

Mr. Andrews' ingenious analysis and suggestions, as also the speculations of unnumbered earnest and meritorious inventors, show the extreme demand for an institute in America where all questions in the basic science of aerial locomotion can be investigated by a laboratory like that of Eiffel, or several others of ample endowment in European countries. It was unfortunate for American prestige in aviation when Langley's for American prestige in aviation when Langley's tion were subjected to official secrecy, and finally discontinued for lack of funds.

${ }^{1}$ The modern type of wing reversely curved at its rear, like a bird's wing under heavy sustaining pressure, was proposed for a practical aeroplane, on account of its superior
longitudinal stability, by Maj. J. D. Fullerton, R. E. (coiner of the terms "lift" and "drift") in a paper read before the aeronautical congress held in Chicago in 1893. Turnbull in 1907, and Eiffel four years later, studied Fullerton's wing
profle, and both commended its stability; but Eiffel found profle, and both commended its stability; but Eiffel found its lift-thrust ratio small as compared with that of standard
forms. At fine incidences the center of lift is at the front forms. At fine incidences the center of lift is at the front
edge of the wing, showing obviously that at some points further back the resultant unit pressure must be downward-

certain, that we can put this powder in our storehouse at less than 75 cents per ton-which, in this country of high wages is much better than Lieut. Ekelund has done, and my own conviction is that we can collect this powder at less than 25 cents per ton if our bog were a large one and our automobile collector were completed.

As to our experience with firing with peat dust, our reat difficulty was the grinding. We would wear of a set of plates in a day, and the dust and noise of operating the grinder were intolerable. It was a very efficient steam raiser, however; was simple to operate and did not injure the boilers. But as wood was plentiful and the drying and grinding so difficult, we gave up using it as a fuel two years ago. But if I was assured that some efficient means of grinding the peat could be had I would return to it again, as it was a cheap and efficient means of raising steam.

Fire-proof Stove Varnish.-Black: Gilsonite or asphalt, copal and linseed oil, with the addition of some Rundschau, excellent stove varnish, the temperature and duration of burning-in increasing with the proportion of oil. For practical recipes, price and the temperature at which burning-in is to be effected are prescribed and this governs the composition. As a rule, compositions of gilsonite, stearine, pitch, Manila copal, hardened rosin and wood oil are used, for instance, 25 parts gilsonite, 3 parts stearine pitch, 3 parts Manila copal melted, 5 parts hardened rosin, 10 parts of wood oil (thick oil boiled with litharge and manganese), 5 parts pine tar, 10 parts of oil siccative. The composition is thinned to brushing or dripping consistency with sangajol, and is said to furnish a good stove varnish. Silver: 10 parts of melted Manila copal, 8 paits thick oil (from linseed oil) 3 parts aluminium bronze, addition of oil of turpentine until of painting consistency. White: Dammar and Stove temperature 60 deg. Cent. (140 deg. Fahr.). 